\title{
Special Issue on Carburization and Metal Dusting
}

\author{
C. Desgranges ${ }^{1,2}$ (D) B. Pint ${ }^{3} \cdot$ D. Monceau ${ }^{4}$
}

Received: 15 February 2017/Published online: 22 March 2017

(C) Springer Science+Business Media New York 2017

Presented in this focus issue of Oxidation of Metals are key papers that deal with carburization and metal dusting, two forms of carbon attack that are important to numerous industrial applications, such as power generation (gas-cooled reactor, sodium-cooled reactor, concentrated solar power) and syngas production.

The atmospheres encountered in many advanced industrial processes are very rarely single oxidant, as illustrated by most of combustion gases which invariably contain carbonaceous species, water vapor, and quite commonly sulfur species derived from the impurities present in most fossil fuels. In other environments, such as liquid sodium, carburization phenomena may be induced by the release of carbon from other system components in the media. Several papers presented in this topical issue also concern $\mathrm{CO}_{2}$ gas as the "sole" environmental constituent-but under pressurized conditions (supercritical $\mathrm{CO}_{2}$ for one case) or with trace constituents present as pollutant. Finally, the different studies of this focus issue concern various

C. Desgranges: Topic Editor; B. Pint and D. Monceau: Guest Editors

C. Desgranges

clara.desgranges@safrangroup.com

B. Pint

pintba@ornl.gov

D. Monceau

daniel.monceau@ensiacet.fr

1 CEA-Saclay, 91191 Gif-sur-Yvette Cedex, France

2 Present Address: Safran Paris-Saclay, Rue des Jeunes Bois, Châteaufort, CS 80112, 78772 Magny-Les-Hameaux, France

3 Materials Science and Technology Division, Oak Ridge National Laboratory, Oak Ridge, TN 37831-6156, USA

4 CIRIMAT, CNRS, INP Toulouse, ENSIACET 4 Allée Emile Monso, BP 44362, 31030 Toulouse Cedex 4, France 
complex experimental environments, but all leading to high-carbon-activity conditions.

Most of the papers deal with industrial materials (austenitic and ferritic steels, base $\mathrm{Ni}$ alloys) and the motivation of the works are lifetime prediction, anticipation of breakaway or determination of conditions leading to inhibition of the corrosion phenomena. Consequently, several of these studies concern quite long-time experimental tests (up to 20,000 hours). New methods to better characterize the very complex morphologies of these types of corrosion phenomena are also proposed in several works.

Within this extended and complex framework of carburizing environments, experimental results are discussed and interpreted on the basis of established thermodynamic and kinetics data, such as chemical activities and diffusion coefficient in the alloys, partial pressure and also velocity of gases and catalytic nature of the sample surface. Comparison of carburization kinetics with internal oxidation kinetics is also effectively discussed.

The following key papers stem from presentations that were given at the Ninth International Conference on High Temperature Corrosion and Protection of Materials (HTCPM2016), which was held at Les Embiez Island, France, on 15-20th of May 2016. 